\title{
Landsat Time Series Analysis for Modelling Temporal Probability for Landslide Occurrences in Curvature Subcarpathians, Romania
}

\author{
Ionuţ ŞANDRIC ${ }^{1}$ and Zenaida $\mathrm{CHIŢU}^{2}$ \\ ${ }^{1}$ Faculty of Geography, University of Bucharest/Romania · ionut-cosmin.sandric@g.unibuc.ro \\ ${ }^{2}$ Faculty of Geography, University of Spiru Haret, Bucharest/Romania
}

This contribution was double-blind reviewed as extended abstract.

\begin{abstract}
The assessment of temporal probability of landslides occurrence requires understanding the factors that control the stability of slopes. These factors are classified in predisposing (geomorphology, geology, etc.) and triggering factors (precipitation or earthquakes). Some of these factors remain constant over time (like geology), some are in a constant change (like land-use and land-cover) and some are rapidly changing their state (like rainfall intensity). If geology can be mapped in the field and rainfall can be measured with rain gauges, the changes in land-cover related to phenological phases are more difficult to measure and map. For the latter, the use of satellite images has been proven the most reliable solution. The present study uses Landsat archive for modelling the changes of rainfall interception over time as the result of phenological changes in land-cover. Over 300 Landsat scenes from 1973 until 2011 were used to calculate leaf area index (LAI). LAI has an important contribution in the rainfall interception model with direct impact on the landslides hydrological model. The spatial and temporal probability of landslides occurrence is calculated using Bayesian Dynamic Network (BDN). The factors for BDN are mapped or derived with deterministic analyses. The model is running in monthly time steps and the results are validated with recorded landslides, triggered in different time periods. For each occurrence of a landslide the local and temporal conditions (including the modelled and the observed values) are stored and statistically analysed.
\end{abstract}

\section{Introduction}

The late changes in climate with increasing severe rainstorm and hot dry seasons have raised the occurrences of natural hazards in Subcarpathian areas (BALTEANU et al. 2010). Heavy rainstorms from 1997 and especially the period from 2005 to 2010 have triggered a high number of landslides in the area of Breaza and the neighbouring villages (SANDRIC 2008). Even though the landslides did not cause loss of life, they caused important material damage, especially to houses and roads located on hill-slopes, where urban and rural infrastructure is missing or is in a very poor condition (badly maintained roads, leaking pipes and sewage) (MIHAI et al. 2010). This has an important impact upon future human activity in this area, especially with the building of a new motorway in Romania that will connect 
the Black Sea with the European motorway network. This new motorway is designed to pass along the bottom of the Prahova River Valley, where susceptibility to landslides is very low, but it can still be affected by future landslides or earth-flows running out onto this area. Once these movements are triggered, they could slide or flow, bringing down significant volumes of debris that could block the road. This situation has occurred in nearby areas located south of the study area on the terrace scarp of Campina. Here several earthflows are active and from time to time flow and cover parts of the National road number 1 (E 60). So far there has been no significant damage or human loss recorded, but it still represents an area with high risk. Considering the importance of landslide monitoring, this study attempts to use Landsat data to model changes of rainfall interception with direct impact on rainfall threshold triggering landslides.

\section{Study Area}

Breaza town is located in the Curvature Subcarpathians and is composed from ten settlements spread on an area of about 50sqkm. The town is well known in Romania for a high landslide activity in the last decades that produced considerable damages to infrastructure and houses. With altitudes ranging from 400 meters in the southern part to about 800 meters in the north western part, the relief of Breaza town is predominantly formed from hills with a mean slope gradient of $20^{\circ}$. From a geological point of view the area is located on a syncline oriented from south-east to north-west and heterogeneous lithology formed from clay and marls frequently alternating with sandstone, conglomerate, gypsum, gravel and sand (DAMIAN et al. 2003). The study area has a drainage density with values from 0.3 to $1 \mathrm{~km} / \mathrm{sqkm}$, with complex network of gully and torrential channels. In the last 25 years the Prahova river has cut a deep and steep channel that played an important role on the activity on the landslides located on the terrace scarps. Along the centuries the natural vegetation was almost entirely removed and it has been replaced with meadows and orchards, mainly apple and prunes (CHITU 2010) orchards are mainly located on the land slides and the low rainfall interception rate combined favourable lithology makes them highly susceptible to landslide occurrence. Similar conditions are on meadows where the infiltration rate is sometimes favoured by the presence of domestic animals. The climate conditions are favourable for landslide occurrence, with mean annual precipitation of $800 \mathrm{~mm}$, mostly in spring and autumn. The rainfall threshold for triggering landslides has been calculated to be $100 \mathrm{~mm}$ in $24 \mathrm{~h}$ (SANDRIC 2008) and $300 \mathrm{~mm}$ in a longer time period for deep seated landslides (CHITU 2010).

\section{Methods}

The Landsat images were downloaded from http://earthexplorer.usgs.gov website for a time interval from 1973 until November 2011. No custom filter, like cloud cover, was applied for data selection, in order to obtain as many images as possible. All the images were batch processed and calibrated to reflectance using a custom Python script. For each Landsat scene the leaf area index (LAI) and fraction vegetation cover (FVC) were calculated. These are important variables in hydrological models and surface balance models (VAN DER KWAST 2009). The LAI and FVC indexes were calculated with the following equations (VAN DER KWAST 2009): 


$$
\begin{aligned}
& L A I=\sqrt{N D V I \frac{1+N D V I}{1-N D V I}} \\
& F V C=\left(\frac{N D V I-N D V I_{\min }}{N D V I-N D V I_{\max }}\right)^{2}
\end{aligned}
$$

With LAI and FVC calculated based on each Landsat scene, the seasonal changes in landcover can be incorporated in Bayesian Dynamic Network (BDN) model (figure 1). For each monthly time step the mean values for LAI and FVC (calculated based on all the images collected in one month) are estimated and used in the hydrological model. The BDN model calculates for each monthly time step the posterior probability of a landslide to occur based on the prior knowledge from previous time steps and the conditional probability for that time step.

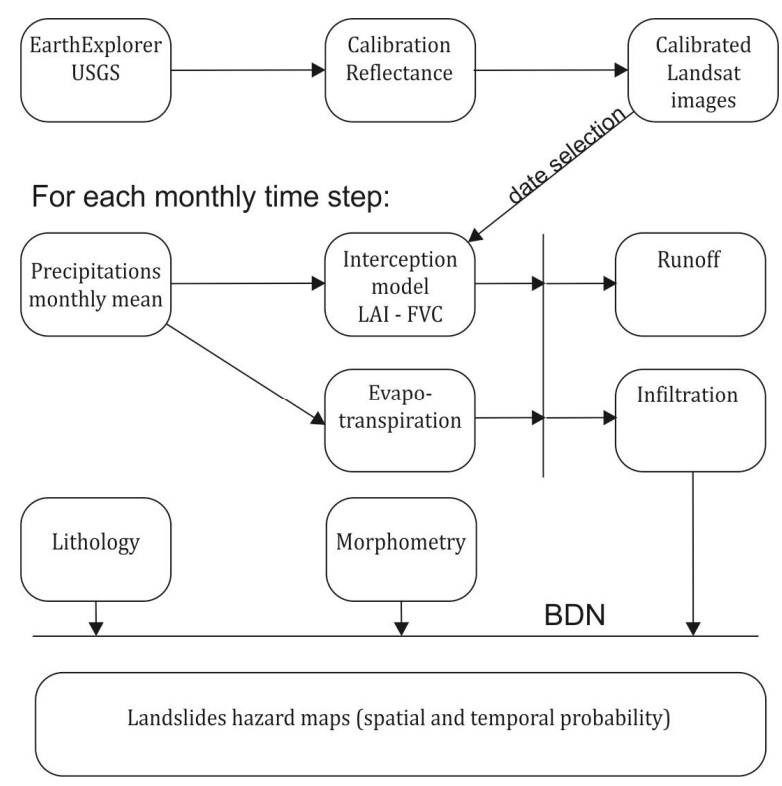

Fig. 1: Schema of the landslides' spatial and temporal probability model

\section{Results}

For the area of Breaza town, over 300 Landsat images were processed for a period of time from 1973 until 2011 (figure 2). The NDVI, LAI and FVC products were used in two important components of the landslide hazard model: interception and evapotranspiration. This has made possible to model not only the changes in land-cover, but also their contribution in the spatial and temporal relationship between rainfall and landslide occurrences. The rainfall threshold triggering landslides has been validated to be around $300 \mathrm{~mm}$ for longer periods of time with low and moderate rain intensity. 


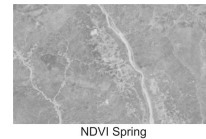

NDVI Spring
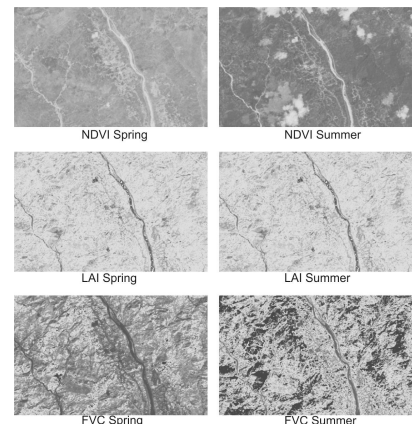

Fig. 2: Changes in NDVI, LAI and FVC for each season

\section{Conclusion and Outlook}

Landsat archive is an excellent source of data to understand and model changes in landcover and land-use. Products derived from Landsat images can be successfully incorporated in complex dynamic models, especially for those that are running very long periods of time. NDVI, LAI and FVC derived from Landsat images had an important contribution in understanding the relation between landslides and rainfall as triggering factor in the area of Breaza town. Similar models can be used in the future, based on the new Landsat 8 and the ESA Sentinel program.

\section{References}

Balteanu, D., Chendes, V., Sima, M. \& Enciu, P. (2010), A country wide spatial assessment of landslide susceptibility in Romania. Geomorphology, 102-112.

ChItU, Z. (2010), Predictia spatio-temporala a hazardului la alunecari de teren utilizand tehnici SIG. Studiu de caz arealul subcarpatic cuprins intre Valea Prahovei si Valea Ialomitei. Bucharest, $\mathrm{PhD}$ thesis.

DAMIAN, R., ARMAS, I. \& SANDRIC, I. (2003), Controlul structural-geologic si morfologic in stabilitatea versantilor subcarpatici; conditii climatice si hidrologice. In: ARMAS, I., DAMIAN, R., SANDRIC, I. \& OSACI-COSTACHE, G. (Eds), Vulnerabilitatea versantilor la alunecari de teren in sectorul subcarpatic al Vaii Prahova. Bucharest, Fundatia Romania de Maine, 37-79.

Mihai, B., SAndric, I., SAvulescu, I. \& Chitu, Z. (2010), Detailed Mapping of Landslide Susceptibility for Urban Planning Purposes in Carpathian and Subcarpathian Towns of Romania. In: GARTNER. G. \& ORTAG, F. (Eds.), Cartography in Central and Eastern Europe. Lecture Notes in Geoinformation and Cartography. Berlin/Heidelberg, Springer, 417-429.

SANDRIC, I. (2008), Temporal GIS for natural hazards assessment. A Bayesian approach with error propagation. Bucharest, $\mathrm{PhD}$ thesis.

VAN DER KWAST, J. (2009), Quantification of top soil moisture patterns: Evaluation of field methods, process-based modelling, remote sensing and an integrated approach. Utrecht, KNAG/Fac. Geowetenschappen. 